\title{
Improved Bioactive Metabolite Production by Saccharopolyspora halotolerans VSM-2 using Response Surface Methodology and Unstructured Kinetic Modelling
}

\author{
Ushakiranmayi Managamuri ${ }^{1}$, Muvva Vijayalakshmi ${ }^{*}$, Mani Deepa Indupalli ${ }^{1}$, Venkat Siva Rama Krishna Ganduri ${ }^{2}$, \\ Satish Babu Rajulapati ${ }^{3}$, Sudhakar Poda ${ }^{4}$
}

\author{
Ushakiranmayi \\ Managamuri', Muvva \\ Vijayalakshmi ${ }^{1 *}$, \\ Mani Deepa Indupalli1, \\ Venkat Siva Rama Krishna \\ Ganduri², Satish Babu \\ Rajulapati ${ }^{3}$, \\ Sudhakar Poda ${ }^{4}$

\begin{abstract}
'Department of Botany and Microbiology,
Acharya Nagarjuna University,

Nagarjuna nagar, Guntur-52510,

Andhra Pradesh, INDIA.

${ }^{2}$ Department of Biotechnology,

KL University, Vaddeswaram, Guntur,

Andhra Pradesh, INDIA.

${ }^{3}$ Department of Biotechnology, National Institute of Technology, Warangal, Telangana, INDIA

${ }^{4}$ Department of Biotechnology, Acharya

Nagarjuna University, Nagarjuna

nagar, Guntur-52510, Andhra Pradesh,

INDIA.
\end{abstract}

\section{Correspondence}

\section{Prof. Muvva Vijayalakshmi}

Acharya Nagarjuna University, Nagarjuna nagar, Guntur-522510, Andhra Pradesh, INDIA.

Phone no : +91-9440870026

E-mail: profmv108@gmail.com

History

- Submission Date: 16-02-2018;

- Review completed: 14-03-2018;

- Accepted Date: 27-06-2018

DOI : 10.5530/pj.2018.5.142

Article Available online

http://www.phcogj.com/v10/i5

\section{Copyright}

(c) 2018 Phcog.Net. This is an openaccess article distributed under the terms of the Creative Commons Attribution 4.0

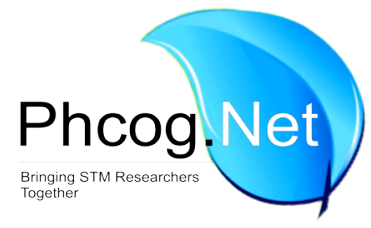

\begin{abstract}
Background: This study targets to optimize and analyse the interactive effects of process variables for improved bioactive metabolite production using RSM and unstructured kinetic modelling by S. halotolerans VSM 2. Materials and Methods: RSM was applied to optimize the interactive effects of five variables, viz., time of incubation, $\mathrm{pH}$, temperature, concentration of maltose and meat extract on bioactive metabolite production and its effect against the five responses viz., S. flexneri, S. marcescens, P. vulgaris, P. aeruginosa and E. coli. Models of Logistic and Luedeking-Piret were used to simulate the cellular increase and bioactive metabolite production. Results: RSM optimal conditions for the bioactive metabolite production recorded were incubation time (12days), $\mathrm{pH}(8)$, and temperature $\left(25^{\circ} \mathrm{C}\right)$, concentrations of maltose and meat extract $(1 \% \mathrm{w} / \mathrm{v})$ (each). The effect of the bioactive metabolite produced (zone of inhibition) against the responses were found to be $17 \mathrm{~mm}$ for $S$. flexneri, $17 \mathrm{~mm}$ for $S$. marcescens, $16 \mathrm{~mm}$ for $P$. vulgaris, $17 \mathrm{~mm}$ for $P$. aeruginosa and $18 \mathrm{~mm}$ for $E$ coli. The data obtained from experimental values are in close agreement with the predicted values of RSM. Model adequacy was evaluated using ANOVA variance where the quadratic effect of $p<0.0001$ which imply the significance of the model. The unstructured-, mathematical- kinetic models provided a better approximation of profiles of $S$. halotolerans VSM 2 growth, optimized media utilization and bioactive metabolite production. Conclusion: Optimization of the independent variables for the production of the bioactive metabolite using RSM by S. halotolerans VSM 2 and its effect against the five responses were documented. The predicted values are in good agreement with the experimental values. Unstructured models provided a better approximation of kinetic profiles for bioactive metabolite production by S. halotolerans VSM 2.
\end{abstract}

Key words: Saccharopolyspora halotolerans, Response surface methodology, Optimization, Bioactive metabolites, Kinetic modelling.

\section{INTRODUCTION}

Nature's extreme environments are untapped immense potential resources for discovery and isolation of novel microbes that are taxonomically significant. These microbes are an essential treasure for novel bioactive lead compounds which might be a consequence of their evolution and adaptation to metabolic biochemistry such as enzymes and antibiotics. ${ }^{1}$ Hence marine microbes offer novel biocatalysis and value added molecules. ${ }^{2}$ Marine microbial diversity enacts limitless pool of novel metabolite chemistry that contributed an important source to the innovative biotechnology. ${ }^{3}$ The search for novel antibiotics from the terrestrial microbes have diminished since this resource has been extensively explored and precious compounds have been already derived from these microbes. ${ }^{4}$ Hence the researchers and scientists switched over to explore new environments for the discovery of pharmaceutical compounds to combat human pathogens.
Actinomycetes are an important group of microbes that dwell in diverse ecological extreme environments $s^{5}$ and are assuring sources for the unconventional anti-microbial compounds that are exclusive and carry unexplored metabolic pathways even at the species variants. ${ }^{6}$ The production of the bioactive compounds by the actinomycetes is influenced by the potency of the strain, nutritional and physical conditions, since the metabolism of the strain influenced by the medium constituents for the production of the bioactive compounds. Several environmental factors including temperature, $\mathrm{pH}$ and incubation period greatly influence the metabolite production in addition to carbon and nitrogen source. $^{7}$

Response Surface methodology (RSM) is a competent statistical method for model development and optimization of the complex process variables for

Cite this article: Managamuri U, Vijayalakshmi M, Indupalli MD, Ganduri VSRK, Rajulapati SB, Poda S. Improved Bioactive Metabolite Production by Saccharopolyspora halotolerans VSM-2 using Response Surface Methodology and Unstructured Kinetic Modeling. Pharmacog J. 2018;10(5):833-40. 
the bioactive metabolite production due to its efficiency and experimental interpretation. ${ }^{8}$ The key features of the RSM application are the reduced number of the experiments accompanied with the process variables interaction effects. ${ }^{9}$ Hence RSM has been widely applied to design the model for the optimization of bioactive metabolite production which accomplishes it, as an expedient and acceptable method to that of classical optimization method. ${ }^{10}$

Mathematical models provide the complete knowledge of dynamic behavior that allows us to operate, optimize and control most of the fermentation processes. When unstructured models are applied for bioactive metabolite production, they would explain the kinetic relationships between substrate, product and biomass. These models obtained from stoichiometry and kinetic expressions describe each operation unit as reactor. Batch bioprocesses are hard to model, owing to the time-varying characteristics of cell systems, which often results in nonlinearities. For this purpose, model equations are solved, and the values of output variables are obtained as a function of time. Further, the evaluation of assumed unstructured model with experimental data for comparison is carried out, to find the best model that could describe the whole microbial system. Parameters estimation is an essential step in the model verification and subsequent use of a mathematical model. In general, unstructured models consider the cell mass to explain the biological system and are more effective in elucidating the fermentation profiles of microbial process for bio products. ${ }^{11-13}$

As the statistical methods viz., Full-factorial design cannot investigate the second order effects of process parameters and Taguchi design does not evaluate the interaction effects of parameters, the present study has been conducted with the following objectives: (i) to optimize the independent process variables using Central composite design of RSM which determines the optimal values and the interactive effects of the independent variables for the bioactive metabolite production by Saccharopolyspora halotolerans VSM 2 and its effect against the five responses. (ii) to assess the kinetic parameters (after verification of mathematical model) in the bioactive metabolite production by Saccharopolyspora halotolerans VSM 2.

\section{MATERIALS AND METHODS}

Isolation

Marine sediment samples were collected at different depths of the Bay of Bengal of north coastal Andhra Pradesh, India. Samples collected were transported to the laboratory in sterile bags and air dried at room temperature and then subjected to pre-treatment with dry heat at $100^{\circ} \mathrm{C} /$ one $\mathrm{h}^{14}$ to increase the actinobacterial population in the sample and to restrain the unwanted contaminants like fungi and bacteria. Pre-treated sediment sample $(1 \mathrm{~g})$ was suspended in $100 \mathrm{ml}$ sterile distilled water, homogenized by vortexing. Serial dilutions were prepared and $100 \mu \mathrm{l}$ of $10^{-4}$ dilution was spread, on Bennett's agar containing $0.1 \%$ yeast extract, $0.1 \%$ beef extract, $0.2 \%$ casein enzymic hydrolysate, $1 \%$ dextrose and $2 \%$ agar ( $\mathrm{pH} 8)$ supplemented with nalidixic acid $\left(50 \mu \mathrm{gml}^{-1}\right)$ and nystatin $\left(50 \mu \mathrm{gml}^{-1}\right)$ followed by incubation at $30^{\circ} \mathrm{C}$ for two weeks. Morphologically distinct strain was selectively segregated and maintained by sub culturing on yeast extract malt extract dextrose (YMD) agar medium at $4^{\circ} \mathrm{C}$ for further study.

\section{Identification}

Metabolites of the promising actinomycete strain VSM-2 showed significant antimicrobial activity when compared to other tested isolates. The strain was identified as $S$. halotolerans VSM 2 by polyphasic taxonomy and by16S rDNA gene sequence (Gen Bank No: KT901294). Pure culture was maintained on Yeast Extract Malt Extract Dextrose (YMD) agar medium at $4^{\circ} \mathrm{C}$ for further study.

\section{Experimental Design and Statistical analysis}

Central composite design (CCD) of RSM has been enforced to evaluate the interaction effects among the variables and to design optimized conditions of the variables to predict the compelling values against the responses. ${ }^{15}$ Five effective variables from the classical optimization approach OFAT (one-factor-at-a-time) were selected. The variables selected include, Time of incubation, $\mathrm{pH}$, Temperature, concentration of maltose and meat extract for the production of bioactive metabolites by S. halotolerans VSM 2 and its effect (antimicrobial activity) against the five responses, Shigella flexneri (MTCC 1457), Serratia marcescens (MTCC 118), Proteus vulgaris (ATCC 6380), Pseudomonas aeruginosa (ATCC 9027) and Escherichia coli (ATCC 35218) (Zone of inhibition measured in $\mathrm{mm}$ ). The experimental design consisted of 50 experimental trials and each of the selected variables has been analysed at three levels, low, medium, and high coded as $(-1,0$ and +1$)$ (Table 1$)$.

The following equation represents the coded process variables

$$
x=\left(X_{i}-X_{0}\right) / \Delta X
$$

The interactive effect of the process variables for bioactive metabolite production was studied for the three values for each factor (minimum, mean and maximum) by full factorial design. The number of experiments $n$ for $k$ factors is given as $n=3 k$. The experimental runs have been randomized to reduce the unexpected variability of the observed responses. Experiments were designed according to CCD using a $2^{5}$ full factorial design for five variables that consists 32 factorial points, 10 axial points and 8 replicates. 8 replicates at centre points were used for each categorical variable which incorporates a total of 50 experiments (Table S1) calculated from Eq- $1 .^{16}$

A second order polynomial regression model was employed in the present study in Eq-2. The application of the polynomial equation is linear and quadratic.

$$
Y=\beta_{0}+\sum_{i=1}^{n} \beta_{1} X_{i}+\left(\sum_{i=1}^{n} \beta_{i i} X_{i}\right)^{2}+\sum_{i=1}^{n-1} \sum_{j=i+1}^{n} \beta_{i j} X_{i} X_{j}
$$

Where $\mathrm{Y}$ is the predicted response, $\beta_{0}$ is intercept coefficient, $\beta_{\mathrm{i}}$ is the linear coefficient, $\beta_{\mathrm{ij}}$ are the interaction coefficients, $\beta_{\mathrm{ii}}$ are the quadratic coefficients, $\mathrm{X}_{\mathrm{i}}$ and $\mathrm{X}_{\mathrm{i}}$ are coded values of the five additive variables.

\section{Statistical Analysis}

Design-Expert version 7, was used for the design of experiments, and analysis of variance (ANOVA) was applied to analyse the interactive effects of the variables (Time of incubation, $\mathrm{pH}$, Temperature, Concentration of maltose and meat extract) for the bioactive metabolite production by VSM 2 and its effect against the responses (antimicrobial activity). The analysis of ANOVA summarizes regression coefficients (RC) Eq. (2), sum of squares (SS), Standard error (SE), F-value (F), and $\mathrm{P}$-value. The statistical significance of the model is analyzed by the probability $p$-value. The $p$-value should be $<0.05$ and $<0.01$ for $95 \%$ and $99 \%$ confidence levels for statistical significance of the effects. Lower the value of $p$, the significance of the corresponding coefficient is more. ${ }^{17}$ The fit and quality of the polynomial model was expressed with the value of correlation coefficient $\left(R^{2}\right)$ and adjusted $R^{2}$. If the model coefficient determination $\left(R^{2}\right)$ and adjusted $\left(R^{2}\right)$ values are $>0.9$, suggests that there is a high correlation between the experimental and model predicted values and indicates that the regression model explains the relation between the independent variables and responses..$^{18} 3 \mathrm{D}$ plots were generated by varying two variables with the experimental range with the other variable constant at the central point. ${ }^{19} 3 \mathrm{D}$ response surface analysis determines the optimal regions of the independent and structured variables. ${ }^{20}$ Additionally, numerical optimization was executed to determine the 
optimum values of the independent variables. Further, a meaningful way of analyzing the kinetic behavior of the cell growth, substrate utilization and product formation in the fermentation process is executed through estimation of its kinetic parameters.

\section{Unstructured Model Development}

The proliferation of marine actinomycete with restricting carbon substrates impacts the metabolite production. A set of mathematical and unstructured kinetic models, significantly define the substrate usage and growth-related production formation kinetics in a batch system that were studied by many researchers. ${ }^{21-22}$

Models of Logistic and Luedeking-Piret were used to simulate the cellular increase and antibacterial metabolite production of S. halotolerans VSM 2. The statistics acquired from the models had been used to calculate the specific cell growth rate $\left(\mu_{\max }\right), \mathrm{d}^{-1}$ and unique production rate of bioactive metabolite, $\mathrm{d}^{-1}$. Under desirable growth conditions with no effects of substrate and product inhibition, growth kinetic model of VSM 2(X) (as per Malthus's law), in a batch fermentation is ultimately described as Logistic function: ${ }^{23}$

$$
\frac{d x}{d t}=\mu_{\max } x\left(1-\frac{x}{x_{m}}\right)
$$

In combination with the equation (Eq-3) leads to the Logistic (L) - type model equation that correlates increased growth of cell:

$$
X(t)=\frac{X_{0} e^{\mu_{\max } t}}{1-\frac{X_{0}}{X_{m}}\left(1-e^{\mu_{\max } t}\right)}
$$

$\mathrm{X}$ represents biomass concentration $(\mathrm{g} / \mathrm{L}) \mu_{\max }$ portrays the maximum specific cell growth rate, $\mathrm{d}^{-1}$, and $\mathrm{Xm}$ depicts the maximum biomass concentration $(\mathrm{g} / \mathrm{L})$.

Antibacterial metabolite production can be obtained from growth limiting substrate (optimized media ingredients) and the substrate utilization kinetics may be taken from Modified Leudeking-Piret (MLP) equation:

$$
-\frac{d S}{d t}=r_{s}=\gamma\left(\frac{d X}{d t}\right)+\eta X
$$

In combination with the above equation results Logistic Incorporated Modified Leudeking-Piret (LIMLP) equation:

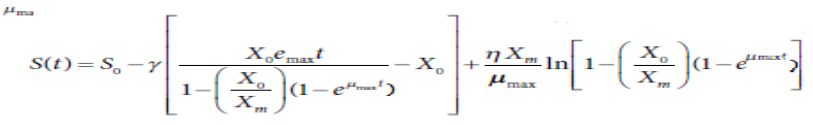

Constant of non-growth associated substrate intake, $\eta$, in equation (Eq-6) can be calculated from stationary phase data

$$
\left(\text { Where } \frac{-d S}{d t}=0\right) ; \eta=\frac{-\left(\frac{d S}{d t}\right)_{\text {stationary phase }}}{X_{\max }}
$$

Considerable bioactive metabolite production occurs in late-logarithmic phase of cell growth and its kinetics follows Leudeking-Piret equation ${ }^{24}$ as:

$$
\frac{d P}{d t}=\alpha \frac{d X}{d t}+\beta X
$$

Logistic Incorporated Leudeking-Piret (LILP) equation derived from integration of above equation results:

$$
P(t)=P_{0}+\alpha\left[\frac{X_{0} e^{\mu_{\max } t}}{1-\left(\frac{X_{0}}{X_{m}}\right)\left(1-e^{\mu_{\max } t}\right)}-X_{0}\right]+\frac{\beta X_{m}}{\mu} \ln \left[1-\left(\frac{X_{0}}{X_{m}}\right)\left(1-e^{\mu_{\max } t}\right)\right](\text { Eq-9) }
$$

Non-growth associated product formation constant, $\beta$, can be determined from stationary phase data (where):

$$
\beta=\frac{\left(\frac{d P}{d t}\right)_{\text {stationary phase }}}{X_{\max }}
$$

Experimental statistics acquired from batch shake-flask fermentations was used to simulate the use of the equations (Eq-4), (Eq-6) and (Eq-9).

\section{RESULTS AND DISCUSSION}

A randomized run of 50 experiments were executed by applying Central composite design of RSM. The influence of the model design matrix on the five variables to produce bioactive metabolite by VSM 2 and its effect on the five responses (zone of inhibition in $\mathrm{mm}$ ) is represented in supplementary Table 1 . The advised sequential model analyses the sum of squares and lack of fit tests for the best outcome quadratic model, for all the five responses. Experimental values of the five responses acquired were in close agreement with the predicted values that indicate the model is gratifying according to the experimental design (Table S1).

\section{CCD analysis of bioactive metabolite production}

CCD of RSM optimized conditions for the bioactive metabolite production by VSM 2 which executes the highest antibacterial activity were found to be 12 days for time of incubation, $\mathrm{pH} 8$, temperature $25^{\circ} \mathrm{C}$, concentration of maltose $1 \%$ and meat extract was $1 \%$. The maximum effect of the bioactive metabolite against the five responses (measured as zone of inhibition in $\mathrm{mm}$ ) were recorded as $17 \mathrm{~mm}$ for $S$. flexneri, $17 \mathrm{~mm}$ for S. marcescens, $16 \mathrm{~mm}$ for P. vulgaris, $17 \mathrm{~mm}$ for $P$. aeruginosa and $18 \mathrm{~mm}$ for E. coli.

Regression analysis of the experimental data was performed, and the model was found to be significant with the $p$-value $(<0.0001)$ for all the five responses. The lower the $p$ value the more significant is the model. The experimental data of each response followed the second-order polynomial equation.

Table 1: Experimental range of factors studied using CCD in terms of coded and actual factors.

\begin{tabular}{ccccc} 
& & \multicolumn{3}{c}{$\begin{array}{c}\text { Actual levels of coded } \\
\text { factors }\end{array}$} \\
\cline { 3 - 5 } Symbols & Independent Variables & $\begin{array}{c}\text { Low } \\
(-1)\end{array}$ & $\begin{array}{c}\text { Medium } \\
(0)\end{array}$ & $\begin{array}{c}\text { High } \\
(+1)\end{array}$ \\
\hline \multirow{2}{*}{$\mathrm{A}$} & Time of Incubation, days & 11 & 12 & 13 \\
$\mathrm{~B}$ & $\mathrm{pH}$ & 7.00 & 8.00 & 9.00 \\
$\mathrm{C}$ & Temperature, ${ }^{0} \mathrm{C}$ & 20 & 25 & 30 \\
$\mathrm{D}$ & Concentration of Maltose, \% w/v & 0.50 & 1.00 & 1.50 \\
$\mathrm{E}$ & Concentration of Meat Extract, & 0.50 & 1.00 & 1.50 \\
& $\%$ w/v & & & \\
\hline
\end{tabular}


Table 2: Sequential model fitting for all the responses (in terms of inhibition zone produced by bioactive metabolite).

\begin{tabular}{|c|c|c|c|c|c|}
\hline $\begin{array}{l}\text { Model } \\
\text { parameter }\end{array}$ & $\begin{array}{l}\text { S. flex- } \\
\text { neri }\end{array}$ & $\begin{array}{l}\text { S. marces- } \\
\text { cens }\end{array}$ & $\begin{array}{l}\text { P. vul- } \\
\text { garis }\end{array}$ & $\begin{array}{l}\text { P. aerugi- } \\
\text { nosa }\end{array}$ & E. coli \\
\hline \multicolumn{6}{|c|}{ Sequential model sum of squares- Quadratic vs 2FI (suggested) } \\
\hline Sum of squares & 75.50 & 116.4 & 61.64 & 75.6 & 176.78 \\
\hline $\begin{array}{l}\text { Degrees of } \\
\text { freedom }\end{array}$ & 5 & 5 & 5 & 5 & 5 \\
\hline Mean square & 15.10 & 23.28 & 12.33 & 15.12 & 35.36 \\
\hline F-value & 122.29 & 263.89 & 190.0 & 168.98 & 308.83 \\
\hline $\begin{array}{c}\text { p-value } \\
(\text { Prob > F })\end{array}$ & $<0.0001$ & $<0.0001$ & $<0.0001$ & $<0.0001$ & $<0.0001$ \\
\hline \multicolumn{6}{|c|}{ Model summary statistics- Quadratic (suggested) } \\
\hline $\begin{array}{l}\text { Standard } \\
\text { Deviation }\end{array}$ & 0.35 & 0.30 & 0.25 & 0.30 & 0.34 \\
\hline $\mathrm{R}^{2}$ & 0.9584 & 0.9799 & 0.9727 & 0.9701 & 0.9821 \\
\hline Adjusted $\mathrm{R}^{2}$ & 0.9296 & 0.9661 & 0.9538 & 0.9494 & 0.9697 \\
\hline Predicted $\mathrm{R}^{2}$ & 0.9447 & 0.9350 & 0.9083 & 0.8878 & 0.9349 \\
\hline $\begin{array}{l}\text { Adequate } \\
\text { Precession }\end{array}$ & 16.641 & 23.200 & 19.282 & 20.105 & 23.570 \\
\hline CV \% & 2.37 & 2.07 & 1.81 & 1.97 & 2.27 \\
\hline
\end{tabular}

Table 3: ANOVA variance to test the adequacy of the model.

\begin{tabular}{cccccc}
\hline \multirow{2}{*}{ Statistics } & \multicolumn{5}{c}{ Response } \\
\cline { 2 - 6 } & $\begin{array}{c}\text { Shigella } \\
\text { flexneri }\end{array}$ & $\begin{array}{c}\text { Serratia } \\
\text { marcescens }\end{array}$ & $\begin{array}{c}\text { Proteus } \\
\text { vulgaris }\end{array}$ & $\begin{array}{c}\text { Pseudomonas } \\
\text { aeruginosa }\end{array}$ & $\begin{array}{c}\text { Escherichia } \\
\text { coli }\end{array}$ \\
\hline $\mathrm{R}^{2}$ & 0.9584 & 0.9799 & 0.9727 & 0.9701 & 0.9821 \\
Adj- ${ }^{2}$ & 0.9296 & 0.9661 & 0.9538 & 0.9494 & 0.9697 \\
Pred- $\mathrm{R}^{2}$ & 0.8599 & 0.9350 & 0.9083 & 0.8878 & 0.9949 \\
Adequate & 16.641 & 23.200 & 19.282 & 20.105 & 23.570 \\
Precession & & & & & \\
CV \% & 2.37 & 2.07 & 1.81 & 1.97 & 2.27 \\
\hline
\end{tabular}

\section{Checking the Model adequacy}

ANOVA variance has been applied to analyze the adequacy of the model at a confidence level of $99 \%$ (Table 3 ). The coefficient of determination $\left(R^{2}\right)$ and the adjusted $R^{2}$ of all the five responses was found to be $>0.9$ (Table 3 ). The Coefficient variation (CV) is the standard deviation expression as percentage (\%) of Mean and need to be less than $10 \%$. CV of the five responses is illustrated in Table 3 . Adequate precision measures the signal to noise ratio and must be greater than 4 for the model to be significant. The outcome of adequate precision is given in Table 3. The CV and the adequate precision of the model executed were found to be significant.

The Fisher's statistical test was employed to determine the importance of each factor where the significance degree was ranked based on the $F$-ratio value (Table 2). The $p$-value of the model for the five responses were statistically significant with the probability F-Value that is $<0.0001$. ANOVA variance analysis reveals most of the significant factors, incubation time (days), $\mathrm{pH}$, temperature, concentration of maltose and concentration of meat extract influence the maximum production of the bioactive metabolite by VSM 2 that effect the five responses (inhibition of growth of the pathogenic microorganisms).
Table 4: Estimated kinetic parameters using L, LILP, LIMLP model equations.

\begin{tabular}{|c|c|c|c|c|c|}
\hline $\begin{array}{c}\text { Kinetic } \\
\text { Parameters }\end{array}$ & $\begin{array}{c}S . \\
\text { flexneri }\end{array}$ & $\begin{array}{c}\text { S. } \\
\text { marcescens }\end{array}$ & P. vulgaris & $\begin{array}{c}P . \\
\text { aeruginosa }\end{array}$ & E. coli \\
\hline \multicolumn{6}{|c|}{ Logistic (L) Model Parameters } \\
\hline$\mu_{\max }\left(\mathrm{d}^{-1}\right)$ & & & 0.72 & & \\
\hline$R^{2}$ & & & 0.99 & & \\
\hline$X_{0}(\mathrm{~g} / \mathrm{L})$ & & & 0.005 & & \\
\hline$X_{\mathrm{m}}(\mathrm{g} / \mathrm{L})$ & & & 0.191 & & \\
\hline \multicolumn{6}{|c|}{$\begin{array}{l}\text { Logistics incorporated Modified Luedeking-Piret (LIMLP) Model } \\
\text { parameters }\end{array}$} \\
\hline$\gamma(\mathrm{g} . \mathrm{S} / \mathrm{g} . \mathrm{X})$ & & & 17.75 & & \\
\hline$R^{2}$ & & & 0.95 & & \\
\hline$\eta($ g.S/(g.X.d)) & & & 0.5235 & & \\
\hline \multicolumn{6}{|c|}{ Logistics incorporated Luedeking-Piret (LILP) Model parameters } \\
\hline $\boldsymbol{\alpha}(\mathrm{mm} / \mathrm{g} \cdot \mathrm{X})$ & 78.37 & 73.17 & 68.97 & 70.22 & 78.50 \\
\hline$R^{2}$ & 0.986 & 0.964 & 0.989 & 0.981 & 0.983 \\
\hline $\boldsymbol{\beta}(\mathrm{mm} /(\mathrm{g} . \mathrm{X} . \mathrm{d}))$ & & & 8.658 & & \\
\hline
\end{tabular}

Table 5: Comparison of zones of inhibition $(\mathrm{mm})$ from shake-flask experiments and from model.

\begin{tabular}{|c|c|c|c|c|c|}
\hline $\begin{array}{c}\text { Maximum } \\
\text { Zone of Inhibition }(\mathrm{mm})\end{array}$ & 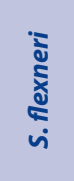 & 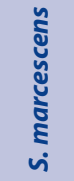 & $\begin{array}{l}\frac{n}{5} \\
\frac{5}{5} \\
\vdots \\
a^{\circ}\end{array}$ & 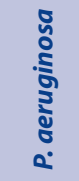 & ڤે \\
\hline Experimental & 27 & 26 & 25 & 25 & 27 \\
\hline Model fitted & 25.97 & 25.01 & 24.23 & 24.46 & 25.99 \\
\hline
\end{tabular}

Interaction effects of the variables

Three-dimensional (3D) surface plots of the five responses illustrated gives the interactive effects of the process variables for maximizing the production of bioactive metabolites. Figure 1-5, represents the 3D plots of the zone of inhibition versus two varying parameters with a fixed value of the third operating parameters. Analysis of the $3 \mathrm{D}$ plots revealed that all the five parameters showed a positive effect. Further increase in the concentration and values of the variables showed decrease in the production of bioactive compounds by S. halotolerans VSM 2 and decrease in the diameter of the zone of inhibition against the responses. The highest production of the bioactive metabolite by $S$. halotolerans VSM 2 was obtained when the time of incubation was 12 days, $\mathrm{pH} 8$, Temperature $25^{\circ} \mathrm{C}$ concentration of Maltose and Meat Extract at $1 \%$.

\section{Unstructured kinetic modelling}

In this study, for fitting of experimental data with unstructured logistic models, nonlinear regression using least-square method was applied with the help of Microsoft Excel Solver 2010. The profiles of S. halotolerans VSM 2 growth limiting substrate utilization results obtained from shake flask experiments and model kinetics were compared in Figure 6(f). Figure 6 (a) - (e) shows the comparison of experimental versus model predicted zones of inhibition of produced bioactive metabolite on media, inoculated with S. flexneri, S. marcescens, P. vulgaris, P. aeruginosa and E. coli strains over the time. From all the profiles, it was observed that model predicted, and experimental obtained values show very good fit. Biokinetic parameters used in the mathematical model equations were 

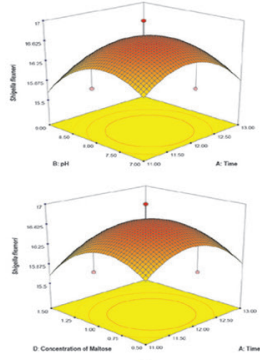

$\mathrm{AB}$

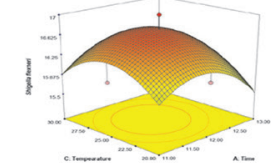

$\mathrm{AC}$

AD

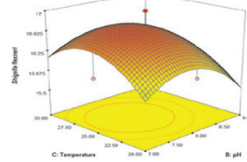

$\mathrm{AD}$

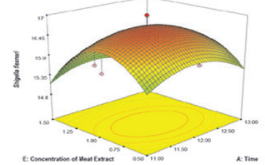

$\mathrm{AE}$

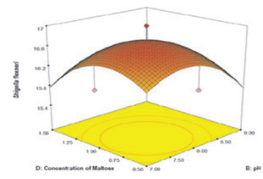

$\mathrm{BD}$

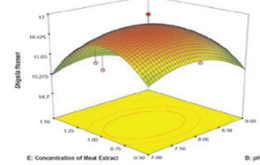

BC

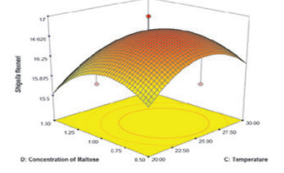

$\mathrm{CD}$

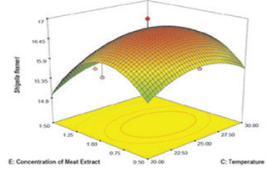

$B E$

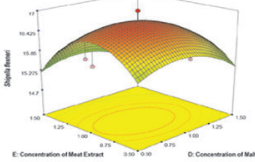

$\mathrm{CE}$

Figure 1: 3D Response surface plots showing interactive effects of selective variables on zone of inhibition $(\mathrm{mm})$ of the bioactive compound production by S. halotolerans VSM-2 against S. flexneri.
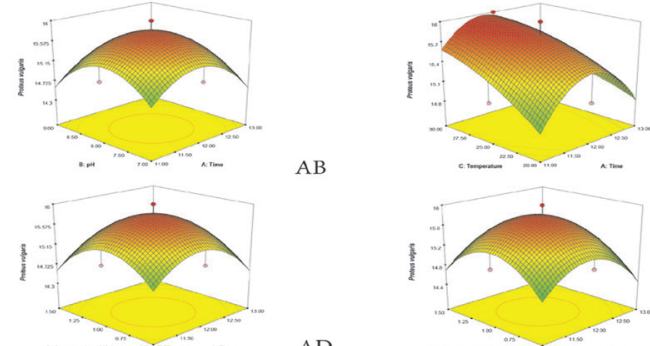

AC
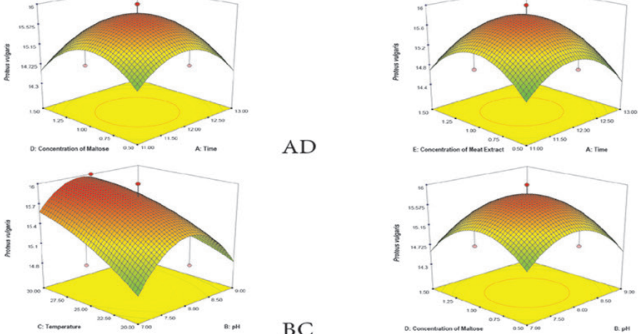

AE
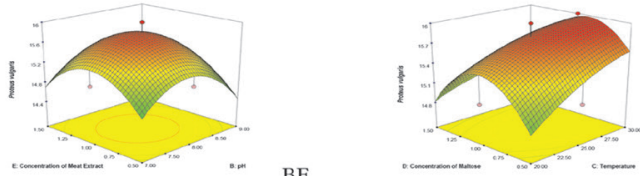

$\mathrm{BD}$

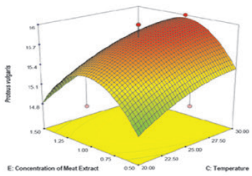

$\mathrm{BE}$

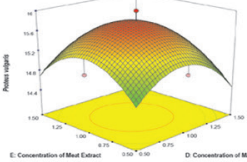

CD

Figure 3: 3D Response surface plots showing interactive effects of selective variables on zone of inhibition $(\mathrm{mm})$ of the bioactive compound production by $S$. halotolerans VSM-2 against $P$. vulgaris.

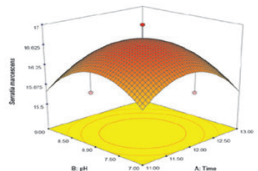

$\mathrm{AB}$

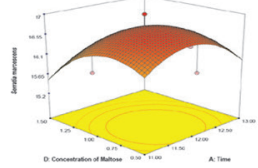

$\mathrm{AD}$
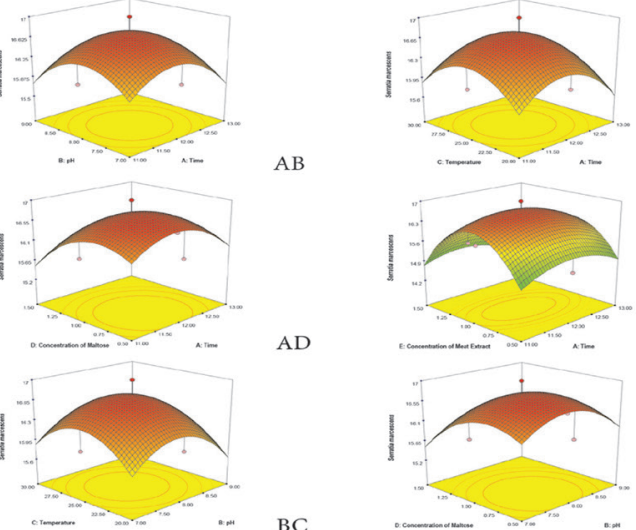

$\mathrm{BD}$

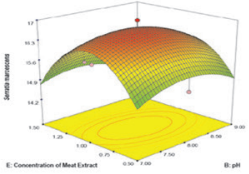

$\mathrm{BC}$

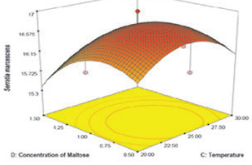

$\mathrm{BE}$
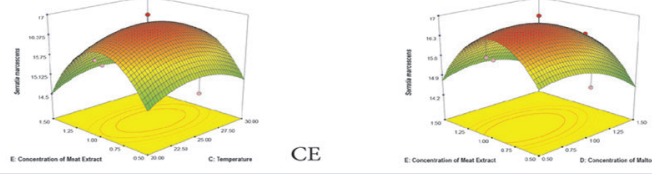

CD

DE

Figure 2: 3D Response surface plots showing interactive effects of selective variables on zone of inhibition $(\mathrm{mm})$ of the bioactive compound production by $S$. halotolerans VSM-2 against $S$. marcescens.

AC

$\mathrm{AE}$
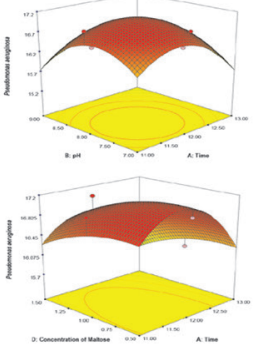

$\mathrm{AB}$

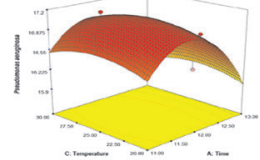

AC

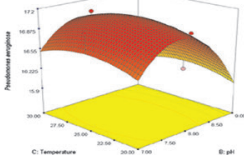

$\mathrm{AD}$

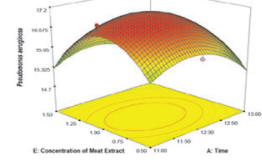

$\mathrm{AE}$

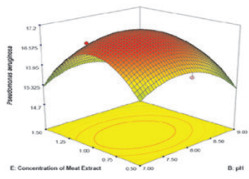

$\mathrm{BC}$

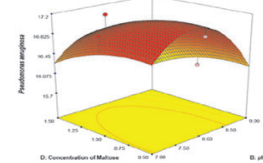

$\mathrm{BD}$

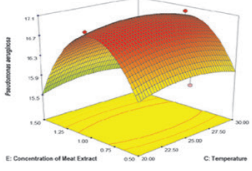

$\mathrm{BE}$

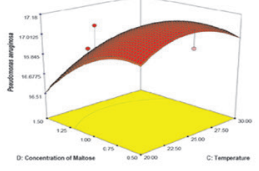

CD

Figure 4: 3D Response surface plots showing interactive effects of selective variables on zone of inhibition $(\mathrm{mm})$ of the bioactive compound production by $S$. halotolerans VSM-2 against $P$. aeruginosa. 


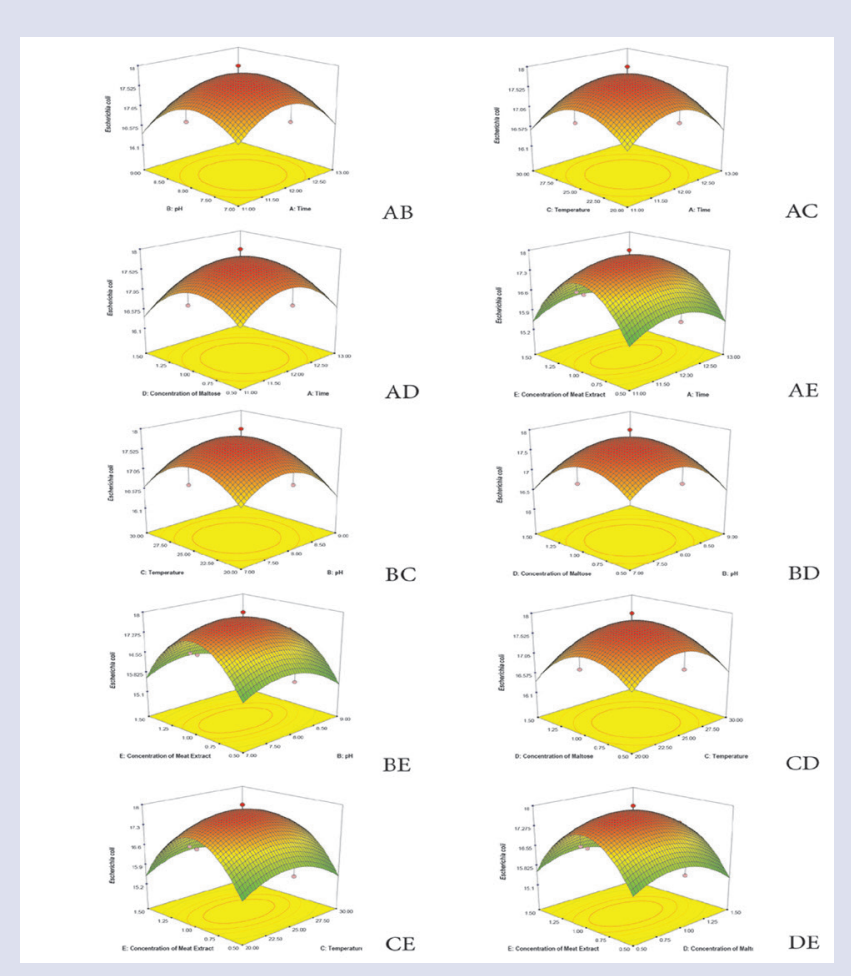

Figure 5: 3D Response surface plots showing interactive effects of selective variables on zone of inhibition $(\mathrm{mm})$ of the bioactive compound production by S. halotolerans VSM-2 against E. coli.

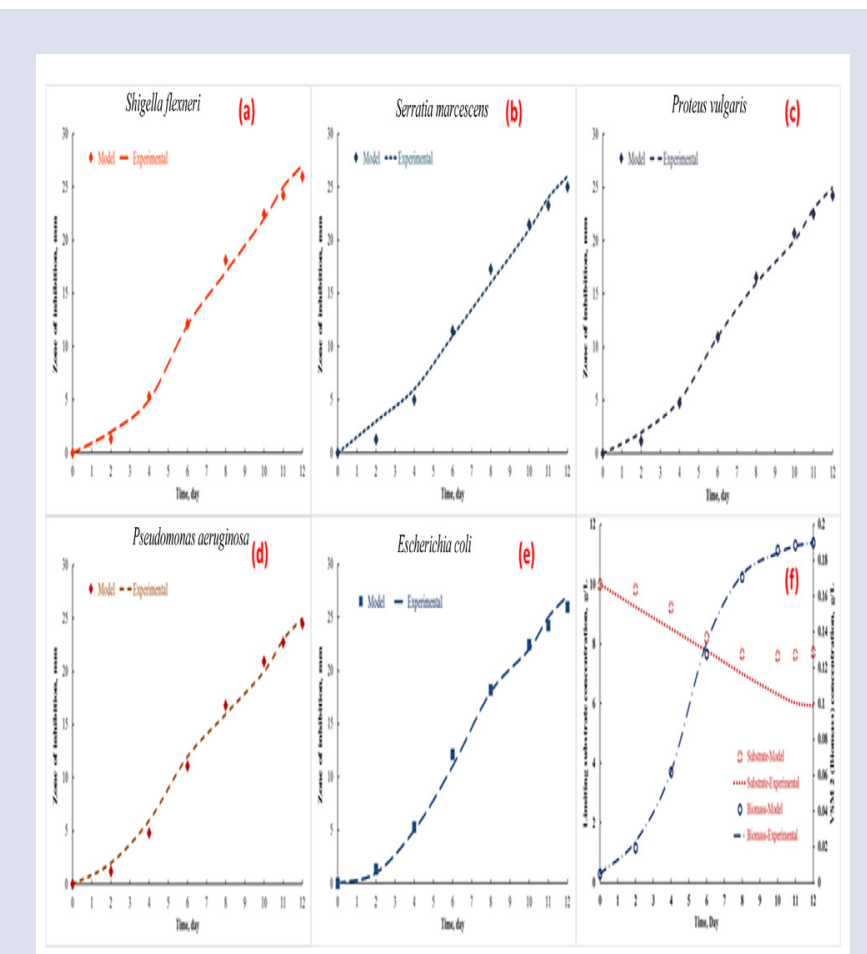

Figure 6: Comparison of experimental and model predicted kinetics (A-E): for zone of inhibition $(\mathrm{mm})$; $(\mathrm{F})$ : for biomass growth $(\mathrm{g} / \mathrm{L})$, substrate utilization $(\mathrm{g} / \mathrm{L})$. also estimated and are tabulated in Table 4 . Table 4 also shows determination coefficient $\left(R_{2}\right)$ values obtained by fitting Logistic $(\mathrm{L})$, Logistic Incorporated Leudeking-Piret (LILP), and Logistic Incorporated Modified Leudeking-Piret (LIMLP) models to the experimental data were found to be high, thus revealing good precision of the models.

From the data of shake-flask used in this study, $\mu_{\max }, X_{0}$ and $X_{\max }$ were calculated from $S$. halotolerans VSM 2 growth kinetic profile using Logistic (L) model. Values of growth and non-growth associated product parameters, $\alpha$ and $\beta$, were estimated using Logistic Incorporated Leudeking-Piret (LILP) model and a higher $\alpha$ values than $\beta$ confirmed that bioactive metabolite production by S. halotolerans VSM 2 is more growth associated than non-growth associated in shake flask. The simulated parameters, $\gamma$ and $\eta$, of Logistic Incorporated Modified Leudeking-Piret (LIMLP) model are also in good agreement with the experimental values, implies that this model is more appropriate to represent limiting substrate utilization kinetics in bioactive metabolite production by S. halotolerans VSM 2. Further, zones of inhibition from agar diffusion tests are almost like model predicted values (Table 5).

Response surface methodology is a statistical and mathematical technique applied for optimizing process parameters and analyzes the interactive effects among the process variables and its effect against the responses. ${ }^{25}$ The CCD of RSM optimized conditions for the production of bioactive compounds by $S$. halotolerans VSM 2 were found to be time of incubation as 12 days, $\mathrm{pH}$ as 8 , temperature as $25^{\circ} \mathrm{C}$, concentration of maltose as $1 \%$ and meat extract as $1 \%$. Zone of inhibition of the growth of the 5 responses by the bioactive metabolite produced by VSM 2 was recorded as $17 \mathrm{~mm}$ for S. flexneri, $17 \mathrm{~mm}$ for S. marcescens, $16 \mathrm{~mm}$ for P.vulgaris, $17 \mathrm{~mm}$ for P.aeruginosa and $18 \mathrm{~mm}$ for E. coli.

Regression analysis was employed to fit the empirical model with the generated response variable data. ${ }^{26}$ The data obtained from the CCD of RSM was fitted into second order polynomial equation. ${ }^{27}$ Considering only the significant independent factors (Table 2), the obtained model indicates the relationship between the predicted results are in agreement with the experimental results obtained.

ANOVA based computation of the predicted and experimental responses determine the polynomial expression of the responses statistically. Adequacy of the model check is essential to check whether the model is suited and to verify that it delivers an accepted approximation to the actual system. ${ }^{28}$ The effect of bioactive metabolite against five responses S. flexneri, S. marcescens, P. vulgaris, P.aeruginosa and E. coli (zone of inhibition in $\mathrm{mm}$ ) produced by the optimization of the independent variables have a significant quadratic effect $(p<0.0001)$. The $p$ value is taken in to account, to review the significance of each of the coefficients and the interactive strength of each parameter. If the $p$ value is found to be less than $<0.05$, it suggests that the corresponding variables are more significant. ${ }^{29}$ The validity of the model was also confirmed by the insignificant Lack fit test values obtained for the five responses $(p>0.05)$ (Table 2).

The coefficient of determination $\left(R^{2}\right)$ shows the proportion of the total variability of the model which suggests the good fit of the model. $R^{2}$ should be close to the value 1 or at least should have a minimum value of not less than $0.80 .{ }^{30}$ The coefficient of determination $\left(R^{2}\right)$ of the five responses was found to be above 0.9 for all the five responses (Table 3 ). Problem with the fit of the model, which always increases with the increase in the added factors even though the factors are not significant. Hence the adjusted $R^{2}$ is used to evaluate the model adequacy since it is adjusted for the number of terms in the model. ${ }^{31} R^{2}$ is adjusted for the size of the model in a way it decreases the insignificant factors added to the model. ${ }^{32}$ The value higher than 0.9 indicates that the regression model explained the procedure well. The coefficient of variation $(\mathrm{CV})$ is the standard deviation expressed as a percentage of the mean and need 
to be less than $10 \% .^{28}$ Adequate precision measures signal to noise ratio, greater than 4 is considered as an adequate signal for the model. ${ }^{33}$ The signal to noise ratio of the developed model of all the five responses is presented in Table 3. In addition, the coefficient of variation $(\mathrm{CV}<10 \%)$ found to be precise and reliable for the experiments. Three-dimensional (3D) surface plots of the five responses illustrated gives the interactive effects of the process variables. Evaluation of the $3 \mathrm{D}$ plots revealed that all the five parameters showed a positive impact. ${ }^{34}$

The profiles of $S$. halotolerans VSM 2 growth limiting substrate utilization results acquired from shake flask experiments and model kinetics of experimental versus model predicted zones of inhibition of produced bioactive metabolite on media, inoculated with S. flexneri, S. marcescens, $P$. vulgaris, $P$. aeruginosa and E. coli strains over the time. From all the profiles, it become determined that model predicted, and experimental obtained values exhibited very good fit. Values of growth and non-growth associated product parameters, $\alpha$ and $\beta$, were estimated using Logistic Incorporated Leudeking-Piret (LILP) model and a better $\alpha$ values than $\beta$ showed that bioactive metabolite production by $S$. halotolerans VSM 2 is more growth associated than non-growth associated in shake flask. The simulated parameters, $\gamma$ and $\eta$, of LIMLP model are also in accurate settlement with the experimental values, means that this model is more suitable to symbolize restricting substrate utilization kinetics in bioactive metabolite production by S. halotolerans VSM 2.

Further, the unstructured models provided a better approximation of kinetic profiles of bioactive metabolite production by S. halotolerans VSM 2 in submerged shake flask fermentations. To the best of our knowledge, this is the first report on the kinetic modelling for bioactive metabolite production (in terms of zones of inhibition studies) by $S$. halotolerans VSM 2.

\section{CONCLUSION}

CCD of the RSM showed the effect against the five responses by the bioactive metabolite produced by $S$. halotolerans VSM 2 . The predicted values of the impact of bioactive metabolite produced against the five responses had been well consistent with experimental values. High values of the adjusted and predicted $R^{2}$ and adequate precession along with low values of the coefficient of variation conclude that the models for responses suit the experimental data adequately. Process parameters optimized was time of incubation 12 days at $\mathrm{pH} 8$, temperature $25^{\circ} \mathrm{C}$ and $1 \%$ concentrations of maltose and meat extract. Further, the unstructured models provided a better approximation of kinetic profiles of bioactive metabolite production by S. halotolerans VSM 2 in submerged shake flask fermentations. To the best of our knowledge, this is the first report on statistical optimization and kinetic modelling for bioactive metabolite production (in terms of zones of inhibition studies) by $S$. halotolerans VSM 2.

\section{ACKNOWLEDGEMENT}

The first author U.K.M is grateful to University grants commission (U.G.C), New Delhi, Government of India, for providing financial assistance.

\section{CONFLICT OF INTEREST}

The authors declare no conflict of interest.

\section{ABBREVIATIONS}

RSM: Response Surface Methodology; CCD: Central Composite Design.

\section{REFERENCES}

1. Satyanarayana T, Raghukumar C, Shivaji S. Extremophilic microbes: Diversity and perspectives. Curr Sci. 2005;89(1):78-90.
2. Singh SP, Thumar JT, Gohel S, Kikani B, Shukla R, Sharma A, et al. Actinomycetes from marine habitats and their enzymatic potential. In: Marine enzymes for biocatalysis, Wood head publishing Series in Biomedicine (Oxford) Ltd., Oxford, UK. 2013;191-214.

3. Fenical W, Jensen PR. Developing a new resource for drug discovery: marine actinomycete bacteria, Nat. Chem. Biol. 2006;2(12):666-73.

4. Hunter PA, Darby, GK, Russell NJ. Fifty years of antimicrobials: past perspectives and future trends. $1^{\text {st }}$ ed. Cambridge University Press. 1995.

5. Goodfellow M, Fiedler HP. A guide to successful bioprospecting: Informed by actinobacterial systematics, Antonie Van Leeuwenhoekl. 2010;98(2):119-42.

6. Ballav S, Kerkar S, Thomas S, Augustine N. Halophilic and halotolerant actinomycetes from a marine saltern of Goa, India producing anti-bacterial metabolites. J Biosci Bioeng. 2015; 119(3):323-30

7. Lin J, Bai L, Deng Z, Zhong JJ. Effect of ammonium in medium on ansamitocin P-3 production by Actinosynnema pretiosum. Biotechnol. Bioprocess Eng. 2010;15(1):119-25.

8. Sheng ZL, Wan PF, Dong CL, Li YH. Optimization of total flavonoids content extracted from Flospopuli using response surface methodology. Ind. Crop Prod. 2013;43:778-86.

9. Deepak V, Kalishwaralal K, Ramkumarpandian S, Babu SV, Senthil Kumar SV, et al. Optimization of media composition for Nattokinase production by Bacillus subtilis using response surface methodology. Bioresour Technol. 2008;99(17):8170-4

10. Souagui $Y$, Tritsch D, Grosdemange-Billiard C, Kecha M. Optimization of antifungal production by an alkaliphilic and halotolerantactinomycete, Streptomyces sp. SY-BS5 using response surface methodology. J Med Mycol. 2015;25(2):108-15.

11. Paz Astudillo IC, Alzate CA. Importance of stability study of continuous systems for ethanol production, J Biotechnol. 2011;151(1):43-55.

12. Charalampopoulos D, Vazquez JA, Pandiella SS. Modelling and validation of Lactobacillus plantarum fermentations in cereal-based media with different sugar concentrations and buffering capacities. Biochem Eng J. 2009;44(2-3):96-105.

13. Olaoye OS, Kolawole OS, Modelling of the kinetic of ethanol formation from glucose biomass in batch culture with a non-structured model. Int J Eng Res Appl. 2013;3(4):562-5.

14. Nonomura YO. Distribution of actinomycetes in soil. A culture method effective for both preferential isolation and enumeration of Microbispora and Streptosporangium strains in soil (Part 1). J Ferment Technol. 1969;47(8):463-9.

15. Box GE, Behnken DW. Some new three level designs for the study of quantitative variables. Technometrics. 1960;2(4):455-75.

16. Azargohar R, Dalai AK. Production of activated carbon from luscar char: Experimental and modelling studies. Micropor Mesopor Mater. 2005;85(3):219-25.

17. Seyed MS, Reyhani A. Optimization of operating conditions in ultrafiltration process for produced water treatment via the full factorial design methodology. Separ Purifi Technol. 2014;132:50-61.

18. Salihu I, Shukor MY, Khalil KA, Halmi MIE, Syed MA, et al. Application of response surface methodology for optimising caffeine-degrading parameters by Leifsonia sp. Strain SIU. J. Env.Biol. 2015;6(5):12215-21.

19. Aslan N. Application of response surface methodology and central composite rotatable design for modelling the influence of some operating variables of a Multi-Gravity Separator for coal cleaning. Fuel. 2007;86(5-6):769-76.

20. Kavitha G, Kurinjimalar C, Siva KK, Kaarthik M, Aravind R, Palani P, et al. Optimization of polyhydroxy butyrate production utilizing waste water as nutrient source by Botryococcusbraunii Kütz using response surface methodology. Int J Biol Macromol. 2016;93(A):534-42

21. Cheng KC, Demirci $A$, Catchmark JM, Puri VM. Modelling of pullulan fermentation by using a color variant strain of Aureobasidium pullulans. J Food Engg. 2010;98(3):353-9.

22. Li HX, Lu ZM, Geng Y, Gong JS, Zhang XJ, et al. Efficient production of bioactive metabolites from Antrodiacamphorata ATCC 200183 by asexual reproductionbased repeated batch fermentation. Bioresource Technol. 2015;194:334-43

23. Leroy F, DeVuyst L. Temperature and $\mathrm{pH}$ conditions that prevail during fermentation of sausages are optimal for production of the antilisterial bacteriocin sakacin $\mathrm{K}$. Appl. Environ Microbiol. 1999;65(3):974-81.

24. Luedeking R, Piret EL. A kinetic study of the lactic acid fermentation. Batch process at controlled Ph. Biotechnol. Bioeng. 1959:1(4):393-412.

25. Wang C, Wang H, Liu Y, Huang L. Optimization of surface treatment for flotation separation of polyvinyl chloride and polyethylene terephthalate waste plastics using response surface methodology. J Clean Prod. 2016;139:866-72.

26. Shahabadi SM, Reyhani A. Optimization of operating conditions in ultrafiltration process for produced water treatment via the full factorial design methodology. Sep Purif Technol. 2014;132:50-61.

27. Kamel MS, Mojtaba M, Mirzakhanlari S, Ellahi R, Vafai K. Numerical investigation and sensitivity analysis of effective parameters on combined heat transfe performance in a porous solar cavity receiver by response surface methodology. Int J Heat Mass Transfer. 2017;105:811-25.

28. Zhang Y, Gao X, Wang C, Zheng Z, Wang L, et al. One-pot stereo selective synthesis of chiral 1, 3-oxathiolane by Trichosporonlaibachii lipase: Optimization by response surface methodology integrated a desirability function approach. J Mol Catal B Enzym. 2016;133:27-34 
29. Xiang $Y$, Xiang $Y$, Wang $L$, Zhang Z. Optimization of foaming properties of sludge protein solution by $60 \mathrm{Co} \gamma$-ray/ $\mathrm{H}_{2} \mathrm{O}_{2}$ using response surface methodology. Radiat Phys Chem. 2016;127:249-55

30. Chen XC, Bai JX, Cao JM, Li ZM, Xiong J, et al. Medium optimization to produce cyclic adenosine 3', 5'-monophosphate by Microbacterium sp. no. 205 using response surface methodology. Bioresour. Technol. 2009;100(2):919-24.

31. Onsekizoglu P, Bahceci KS, Acar J. The use of factorial design for modelling membrane distillation. J. Membr. Sci. 2010;349(1-2):225-30.
32. Montgomery DC. Design and analysis of experiments $5^{\text {th }}$ ed. John Wiley and Sons, New York. 2001

33. Köse TE. Agricultural residue anion exchanger for removal of dye stuff from wastewater using full factorial design. Desalination. 2008;222(1-3):323-30.

34. Ghoreishian SM, Badii K, Norouzi M, Malek K. Effect of cold plasma pre-treatment on photo catalytic activity of 3D fabric loaded with Nano-photocatalysts: Response surface methodology. Appl Surf Sci. 2016;365:252-62.
GRAPHICAL ABSTRACT

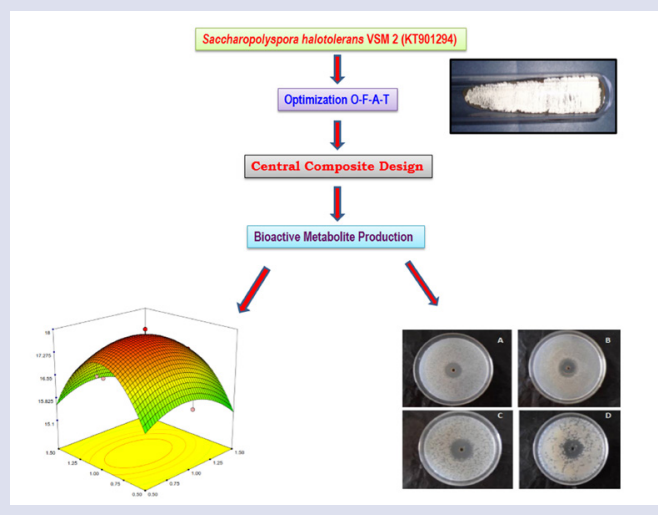

\section{SUMMARY}

- Research designed different process variables affecting the production of bioactive metabolites by Saccharopolyspora halotolerans VSM-2 and its effect against the 5 responses was executed in the laboratory. As a result, the application of RSM was handy and viable to study the effect of the important parameters on the production of bioactive metabolites by Saccharopolyspora halotolerans VSM-2 and its effect against the 5 responses. In addition the mathematical modelling of the process parameters have been executed to also study the process parametes. The accomplishment of the process optimization was feasible with the application of RSM and factorial design. The study clearly demark that RSM is most reliable design to optimize the operating conditions to escalate the production of bioactive metabolite. Full factorial central composite design (50 assays) was successfully operated for the experimental design and the result analysis. The predicted values of RSM are in agreement with the experimental values. Process parameters optimized was time of incubation 12 days at $\mathrm{pH} 8$, temperature $25{ }^{\circ} \mathrm{C}$ and $1 \%$ concentrations of maltose and meat extract for the highest production of the bioactive metabolite. Further, the unstructured models provided a better approximation of kinetic profiles of bioactive metabolite production by $S$. halotolerans VSM 2 in submerged shake flask fermentations.

\section{ABOUT AUTHORS}

Dr. Ushakiranmayi Managamuri: Dr. Managamuri is a UGC-Women Post Doctoral Fellow, She obtained her Ph.D degree in Microbiology from Sri Krishnadevaraya University, Anantapur and Ph.D Degree in Biotechnology from Acharya Nagarjuna University.

Prof. Muvva Vijayalakshmi: Prof Muvva is a Professor in Department of Botany and Microbiology and Dean of Life Science. She had handled a good number of projects and has more than 200 publications

Dr. Deepa Indupalli: She has completed her Masters and Ph.D from Department of Microbiology, Acharya Nagarjuna University.

Dr. Venkat Siva Rama Krishna Ganduri: Dr Rama Krishna completed his B.Tech in Chemical Engineering from NIT Warangal, M.Tech Biotechnology from Anna University and Ph.D in Biotechnology from Acharya Nagarjuna University.

Dr. Satish Babu Rajulapati: Dr. Satish completed his B.Tech in Chemical Engineering from NIT Warangal, and M.Tech Biotechnology and Ph.D in Biotechnology form JNTU hyderabad. He is at present working as Associate Professor, Department of Biotechnology, NIT Warangal.

Dr. Sudhakar Poda: Dr. Poda obtained his Masters from Madras University and Completed his Ph.D form Sri Krishnadevarya University. He is at present working as Coordinator and Assistant Professor in Department of Biotechnology, Acharya Nagarjuna University.

Cite this article: Managamuri U, Vijayalakshmi M, Indupalli MD, Ganduri VSRK, Rajulapati SB, Poda S. Improved Bioactive Metabolite Production by Saccharopolyspora halotolerans VSM-2 Using Response Surface Methodology and Unstructured Kinetic Modeling. Pharmacog J. 2018;10(5):833-40. 